\title{
Agri-food tech discovers silver linings in the pandemic
}

\author{
Madeleine Fairbairn $^{1} \cdot$ Julie Guthman ${ }^{1}$
}

Accepted: 15 April 2020 / Published online: 13 May 2020

(c) Springer Nature B.V. 2020

Perhaps in the recent past you've questioned the need for food delivery bots. We had too, that is, until covid-19 relegated us to our homes, and shopping became the equivalent of entering the Chernobyl exclusion zone. Our curiosity on this point stems from our participation in a collaborative study with agri-food researchers across three University of California campuses (https://afterproject.sites.ucsc.edu/) that is investigating Silicon Valley's recent foray into food and agriculture as sites of innovation and investment. One of our research questions revolves around how the tech sector defines and represents the problems it undertakes to solve. These problems, we've observed, are frequently vast in scope, while the solutions proffered are notably narrower, driven less by public need than by technological availability and investor interest. How has the advent of covid-19-a problem of seismic proportions if ever there was onechanged this industry dynamic?

As the virus has carved its exponential path through our economic and social lives, the agri-food tech sector has undertaken an almost instantaneous repositioning. Industry think pieces rapidly emerged weighing the impact and discovering "Silver Linings from the Dark Cloud of Covid-19" (Albrecht 2020). An open letter from the founder of IndieBio, a biotech incubator that has fostered such food-tech darlings as Clara Foods and Memphis Meats, exhorted its companies to "find opportunity in this crisis," stating that "This pandemic will amplify the need for your existence" (Gupta 2020). An article on AgFunderNews, meanwhile, was quick to point out that venture capitalist investing in agri-food tech are better positioned than almost all of their peers-as essential services, food and agriculture constitute a relatively safe bet given that "the only thing people are buying right now is food" (Pothering and Burwood-Taylor

"This article is part of the Topical Collection: Agriculture, Food \& Covid-19".

Madeleine Fairbairn

mfairbai@ucsc.edu

1 University of California, Santa Cruz, USA
2020). (Apparently, venture capital is less interested in toilet paper.)

So what specific virus-induced shifts are we seeing, or expecting to see, in the sector? One is a pivot in overarching tropes. Since it began to cohere as a self-identified sector about 8 years ago, agri-food tech has laid claim to a range of world-saving ambitions. At pitch nights and innovation summits, we have seen technological fixes promised for everything from climate change to plastic pollution to inhumane treatment of animals. The specter of food insecurity caused by population growth - the oft-referenced ten billion by 2050 - has, of course, been a near constant refrain. Food safety has always featured prominently in this litany of challenges, but it now seems poised to emerge, at least temporarily, as the reigning problematic of ag-tech solutionism. This reorientation makes a certain amount of sense. Neo-Malthusian productivism was always a dubious underpinning given the prevalence of over-production in agriculture (a vast problem about which the tech industry seems curiously unaware), and food safety could actually prove to be a more apposite frame for agri-food tech solutionism.

As Covid-19 gives a new lease on life to a Pasteurian politics of purity, we're also getting a preview of the kinds of technology most likely to benefit. A heightened awareness of animal-borne disease is providing new rationales for cellular meat and other alternative protein products that replace the need for livestock production. Companies involved in indoor vertical agriculture are amplifying claims about the superiority of their highly controlled environments. And concern about hand-to-face transmission of covid-19 is giving new justifications for the touchless harvest and food delivery promised by robotics. Little mention is made of the predominantly minority farm and food service workers who are bearing the brunt of virus exposure now, but whose livelihoods may eventually be lost in the pursuit of sterility that follows. Whether such sterility is even possible to achieve remains a dubious proposition. It is arguable that highly controlled agricultural environments are actually more prone to disease outbreaks and therefore less resilient. They certainly stand in stark contrast to the probiotic sensibility that has long 
undergirded agroecology and these days supports regenerative agriculture. In the long run, that cure may be just as scary as the disease.

Acknowledgements Research discussed herein has been supported by the National Science Foundation (Grant \# 1749184).

\section{References}

Albrecht, Chris. 2020. Silver linings form the dark cloud of COVID-19. The Spoon. https://thespoon.tech/newsletter-silver-linings-fromthe-dark-cloud-of-covid-19/. Accessed 14 April 2020.

Gupta, Arvind. 2020. A letter to our founders. Medium. https:// medium.com/indiebio-sf/a-letter-to-our-founders-f73eb640866. Accessed 14 April 2020.

Pothering, Jessica and Louisa Burwood-Taylor. 2020. Agrifoodtech VCs assess Covid-19's impact on the sector and portfolios. AgFunder News. https://agfundernews.com/ agri-foodtech-vcs-assess-covid-19s-impact-on-the-sector-andportfolios.html?utm_source $=7 \mathrm{k}+$ from $+\mathrm{CM}+$ that + didnt + come +across\&utm_campaign $=7$ ea 35978 be -EMAIL _CAMPAIGN_3_12_2020_COPY_01\&utm_medium=email \&utm_term=0_175df5dcb7-7ea35978be-99074505. Accessed 14 April 2020.

Publisher's Note Springer Nature remains neutral with regard to jurisdictional claims in published maps and institutional affiliations.

Madeleine Fairbairn, PhD, is a sociologist and assistant professor in the Environmental Studies Department at the University of California, Santa Cruz. She studies the political economy of agriculture, including the financial sector's growing interest in acquiring farmland and, more recently, the Silicon Valley agri-food tech sector. Her first book, Fields of Gold: Financing the Global Land Rush is forthcoming in July, 2020 from Cornell University Press.

Julie Guthman, $\mathrm{PhD}$, is a geographer and professor of social sciences at the University of California, Santa Cruz, where she teaches several courses on food and agriculture. Her publications include three multiaward winning monographs, the latest of which, Wilted: Pathogens, Chemicals, and the Fragile Future of the Strawberry Industry, was the recipient of the 2020 AAG Meridian Award for outstanding scholarly work in geography. She is also the recipient of the 2015 Excellence in Research Award from the Agriculture, Food and Human Values Society. 